\title{
Factorial Hidden Markov Models を用いた 部分観測データからの全身運動復元 Whole Motion Recovery from Partial Observation Data using Factorial Hidden Markov Models
}

\author{
$\bigcirc$ 正 李 東姫 (東京大学) 正 クリッチ ダナ (東京大学) 正 中村 仁彦 (東京大学) \\ Dongheui LEE, The University of Tokyo,dhlee@ynl.t.u-tokyo.ac.jp \\ Dana KULIĆ, The University of Tokyo, dana@ynl.t.u-tokyo.ac.jp \\ Yoshihiko NAKAMURA, The University of Tokyo, nakamura@ynl.t.u-tokyo.ac.jp
}

\begin{abstract}
This paper proposes a method to recover missing data during observation by factorial hidden Markov models (FHMMs). By combining the motion recognition from partial observation algorithm and the proto-symbol based duplication of observed motion algorithm, whole body motion imitation from partial observation can be achieved. The algorithm for missing data recovery uses the same basic strategy as the whole body motion imitation from partial observation, but requires more accurate spatial representability. FHMMs allow for more efficient representation of a continuous data sequence by distributed state representation compared to hidden Markov models (HMMs). The proposed algorithm is tested with human motion data and the experimental results show improved representability compared to the conventional HMMs.
\end{abstract}

Key Words: factorial hidden Markov model (FHMM), mimesis, motion recovery

\section{I.はじめに}

神経科学でのミラーニューロンの発見はロボットの模倣学習の研 究に影響を与えた。その中で隠れマルコフモデル (hidden Markov model, HMM) は時系列デー夕を効率的に抽象化するため人間の動 作をモデリングによく使われてきた[1][2] [3].しかし，HMMの利 用では運動認識と運動生成の間でトレードオフがある。特に状態 の数の選択に大きく関連する [4]. 状態数が少ない場合はいい洲化 性能, 認識性能を持つが, 動作の表現力性能が落ちる. 状態数が多 い場合は表現力性能がいい反面，過学習 (overfitting) 問題が起こり やすい. HMM のモデル選択は Bayesian[5] と Akaike [6] 情報を基 準に研究されてきたが，これらは認識だけを考慮したものである. 予测プログラミング (prediction programming) 方法では [7], HMM の構造とパラメタをオンラインで学習する. マニピュレータ軦道予 測の簡単なタスクに適用されたが，人間の運動のような複雑なタス クには検訨されていない.Kulić ら [4]はFHMM を用いた人間動作 表現を提案した。

ヒトの運動の認識生成の実装においては部分観測への対応を解決 しなければならない，著者らは部分観測データからの全身運動の見 真似のアルゴリズムを開発してきた [8][9][10].これらの研究の共 通部分は部分観测からの運動認識アルゴリズムと観測データに条件 付けられた運動生成アルゴリズムである。この二つの方法により， 部分的情報から全身運動の見真似が可能になる。運動データの一部 が欠落した部分観测から全身運動復元も上記の見真似のアルゴリズ ムで䇛現できる。しかし，隠れマルコフモデルの離散的状態から生 じる復元の正確性の限界がある。この問題は認識と生成の間の性能 のトレードオフと類似している．隠れマルコフモデルの状態の数が 少ないと，新しい動作に対する認識の性能は良くなるが生成される 表現力が劣化する。その一方で状態の数が多いと，動作の表現力は 増すが過学習によって，新しい動作に対する認識の性能が悪くなる. また学習の際，計算上のオーバーフローあるいはアンダーフローの 問題がよく起こる。本稿では図 2 のような Factorial 隠机マルコフ モデルを利用した missing データの復元の正確性を高める方法を提 案する。

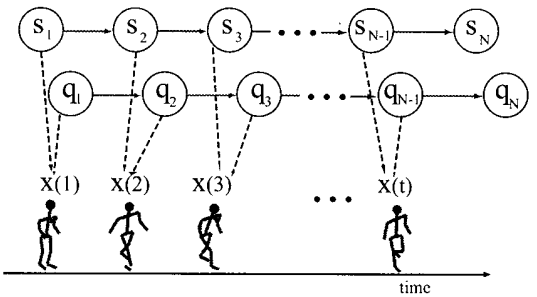

Fig. 1. Factorial Hidden Markov Model

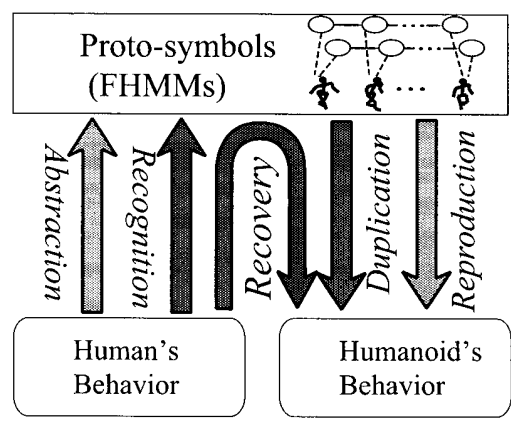

Fig. 2. The proposed strategy: Abstraction is done by the FHMM exact training [11]. Recognition is implemented by an adaptation of the forward-backward algorithm [11]. Reproduction is implemented by the greedy generation algorithm [4] or a stochastic generation algorithm . Algorithms of motion recognition from partial observation and proto-symbol based duplication of observed motion for FHMMs are developed. By combining the two algorithms, missing observation data are recovered accurately.

\section{FHMMによる動作表現}

隠れマルコフモデル (hidden Markov model, HMM) は人間の動 作をモデリングによく使われてきた[1] [3]. Inamura らは [3]HMM を用いてミメシスモデルを提案した。ミメシスモデルに求められる 特徴は, 行動学習, 認識, 生成という亡つの機能を統合することに 
ある，学習では，時系列行動データは原始シンボルとして抽象化さ れる，認識は，観察の最も適当な原始シンボルを見つけることであ る。生成は，原始シンボルからの時系列行動データの出力である.

原始シンボルは HMM のパラメータ $\lambda=\{A, B, \pi\}$ として表現さ れる. $A=\left\{a_{i j}\right\} i$ 番目の状態加 $j$ 番目の状態へ遷移する確率 $a_{i j}$ の集合である状態遷移確率分布, $B=\left\{b_{i}\right\} i$ 番目の状態からoを出 力する確率分布 $b_{i}(o)$ の集合である状態遷移砗率分布, $\pi=\left\{\pi_{i}\right\}$ 初 期状態確率分布で表される。

Factorial hidden Markov model（FHMM）は図 1 に示すように分 散型の状態を持つ隠れマルコフモデルである，FHMM は複数の隱 れマルコフチェーンで構成される。 各チェーンは初期状態確率分布, 状態遷移確率分布, 出力確率分布で表される。データを生成する時, 各チェーンは独立的に時系列行動デー夕を出力し, 全てのチェーン からの出力データの和をとる.

様々な FHMM の学習方法が開発された：Exact 方法 [11], mean field approximation [11], backfitting アルゴリズム [12], sequential training 方法 [13]. Exact 方法 [11] は Baum-Welch アルゴリズムの 適用で，計算負担が高い，その他は Exact 方法より計算量が少ない が，学習性能が Exact 方法より悪い。一旦 FHMM が学習されたら， forward-backward アルゴリズム[11] のアダプテーションで観测デー 夕を認識できる。そして，FHMMからその代表的な時系列データ を生成出来る [4]

従来の HMM に比べて FHMM は表現力の観点から見ると効率的 である．HMMが認識と生成の間でトレードオフを持つ反面，FHMM は認識のためのよりよい劣化性と生成のためのよりよい詳細を結合 する効率的な方法を提供する. HMM でよく直面する状態数が多い 時の過学習 (overfitting) 問題と状態数か少ない時の悪い生成性能を 避けるために, Kulić ら [4] は FHMM を用いた人間動作表現を提案 した.

III. FHMM を用いた MISSING データ復元

実際のアプリケーションにおいては部分観測への対応を解決す べきである．著者らは部分観測データからの全身運動の見真似方法 を開発してきた [8]. 部分観测からの運動認識アルゴリズムと観測 データに条件付けられた運動生成アルゴリズムが提案された。

観测デー夕に条件付けられた運動生成は観測された運動に近い運 動の見真似を可能にする．Viterbi アルゴリズムによって計算された 最適な状態時系列は生成される運動が観测デー夕と時間的同期され るようにする。したがって同じ原始シンボルに対応するやや違う動 作らがそれぞれの違う同期をとることになる。

この二つの方法（部分観测からの運動認識と観测データに条件付 けられた運動生成）により，部分的情報から全身運動の見真似が可 能になる．欠落されたデータの復元もミメシスモデルを使う同じ戦 略で可能となる。しかし，隠れマルコフモデルの離散的状態から生 じる復元の正確性:の限界がある。この問題は認識と生成の間の性能 のトレードオフと類似している，隠れマルコフモデルの状態の数が 少ないと，新しい動作に対する認識の性能は良くなるが生成される 表現力が落ちる，その一方で状態の数が多いと，動作の表現力は増 すが過学習によって次のような問題が生じる，新しい動作に対する 認識の性能が悪くなる。隠れマルコフモデルのパラメータを学習す る際, 計算上のオ一バーフローあるいはアンダーフローの問題が起 こる可能性が増える. 復元の場合, 最適な状態遷移時系列の計算性: 能が落ちる。本稿では図 2 のような Factorial HMM を利用した欠 落されたデータの復元の正確性を高める方法を提案する.

\section{A. 部分観測からの動作認識}

他者の行動を認識は，観測された行動パターンが各原始シンボル によって生成される確率を用いて，複数の原始シンボルの集合から
最大の確率を持つ原始シンボルを求めることである。

$$
\lambda^{*}=\arg \max _{\lambda} P(x \mid \lambda)
$$

Factorial HMM に対して対数尤度 $\log P(x \mid \lambda)$ は forward-backward アルゴリズムのアダプテーションから計算される [11]. 人力行動 データ $x_{t}$ で観测できない行動要素がある時, ガウス分布の線形結 合で表される出力確率分布 $b_{i}\left(x_{t}\right)$ が変更される.

$$
b_{i}\left(x_{t}\right)=\frac{\exp \left\{-\frac{1}{2}\left(x_{t}-\mu_{i}\right)^{T} \Sigma_{i}^{-1}\left(x_{t}-\mu_{i}\right)\right\}}{\sqrt{(2 \pi)^{M} \operatorname{det} \Sigma_{i}}}
$$

観測されてない行動要素 $\left\{x_{k}\right\}_{t}$ に対しては，その欠落された運 動要素が出力確率分布関数に影響与えないように式 (3) 入は式 (4) を代人する。

$$
\begin{array}{r}
\left\{x_{k}\right\}_{t}-\mu_{i j}=* \\
\Sigma_{i j}=\infty
\end{array}
$$

式 (3)の*は定数で, 本稿の実験ではその定数を0にとしている.

\section{B. 観测データに条件付けられた原始シンボルからの運動生成}

運動生成では，運動パターンが原始シンボルから出力される。運 動生成には2つのプロセス（状態遷移列の生成および出力行動要 素の生成）で構成される。不観測運動要素は, 出力運動パターンが 原始シンボルと現在の観測データから生成されることにより復元さ れる。

HMM モデルにおいて与えられた観察データを最もよく表現する 最適な状態系列を求めるアルゴリズムであるViterbi アルゴリズム [14] を用いて最適状態経路を探す。最適経路が得られる後, 出力運 動パターン $y$ がノード $s_{i}$ の出力確率分布 $b_{i}(x)$ によって計算され る. 最適状態経路によって観測デー夕と時間的同期とられた全身運 動の生成が可能になる.

FHMM 用のViterbiアルゴリズムを提案する。(1) N 個の状態を 持つ $\mathrm{M}$ 個のチェーンで表現されている FHMM を $N^{M}$ 個の状態を 持つ HMM へ展開する。 その展開は exact 学習方法から抜き出す [11].（2） $N^{M}$ 個の状態を持つ HMM から観測デー夕を生成する最 適な状態時系列 $S^{*}$ を従来の Viterbi アルゴリズムによって計算す る。時間 $t$ の最適な状態 $s_{t}^{*}$ は 1 から $N^{M}$ 中の整数になる。 (3) シ ングルチェーンの最適な状態時系列 $S^{*}$ を $M$ 個のチェーンに対応 するように変換する。時間 $t$ の $i$ 番目チェーンの最適な状態 $s_{i t}$ は 1 から $N$ 中の整数になる.

最適な状態時系列を計算する際, 出力確率分布が用いる。ここで も，不観測行動要素が出力確率分布関数に影響与えないように，不 観測運動要素に対して式 (3) 入は式 (4) を適用する。最適な状態時 系列に従って，各チェーンの各状態ノ一ドから出力ベクトルを出力 させる，毎時刻，各チェーンからの出力ベクトルの和をとって，出 力時系列パターンを得る。その後，実際のヒューマノイドロボット に与える滑らかな制御人力を求めるためにスムージング技術を使用 する。

FHMM を利用して観測データに条件付けられた運動生成を疑似 コードで要約する.

Step1 FHMM $\lambda$ ( $M$ chains of $N$ states) t HMM $\lambda^{\prime}\left(N^{M}\right.$ states) へと展開する。

Step2 $\lambda^{\prime}$ から当られた観测データを生成する最適な状態時系列 $S^{*}=\left[s_{1}^{*}, \cdots, s_{T}^{*}\right]$ を従来の Viterbi アルゴリズムによって 計算する.

Step3 $S^{*}$ を $M$ 個のチェーンに対応する $S=\left[S^{1}, \cdots, S^{M}\right]^{T}$ に 変換する。 
Step4 最適な状態時系列に従って, 各チェーンの出力ベクトルを 出力させる. 毎時刻, 各チェーンからの出力ベクトルの和を とって, 出力時系列パターンを得る: $y_{t}=\sum_{m=1}^{M} B^{m}\left(s_{t}^{m}\right)$, for $0<t<T$.

\section{IV. 実験}

欠落されている運動要素復元において FHMM の性能を HMM と 比較する. 光学式モーションキャプチャーシステムを使ってキャプ チャ一された行為者の運動データを用いた，ラベリングされたマー カの 3 次元位置デー夕を逆運動学によって 20 白由度のヒューマ， イドロボットモデルにマッピングする，運動データセットには 28 個 の足踏み (step), 15 個の万歳 (cheer), 14 個のダンス (dance), 19 個 のキック (kick), 14 個のパンチ (punch), 15 個の相撲のしこ (sumo stomp), 14 個のうずくまる (squat)，13 個の投げ (throw), 15 個の しゃがみこみ (bow) の 9 種類の動作がある. 図 3 は足踏み行動の 様子である

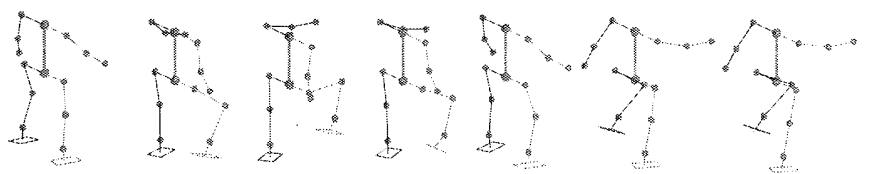

Fig. 3. Sample Walking Motion - Animated from joint angle data provided by the motion capture system. $(1,11,21,31,41,51$ and 61 frames)

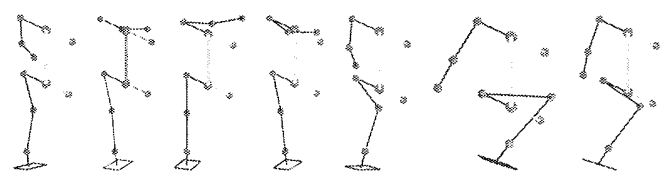

Fig. 4. Partially Observed Walking Motion - Animated from joint angle data. Right shoulder, arm, and leg are invisible. (1, 11, 21,31,41, 51 and 61 frames)

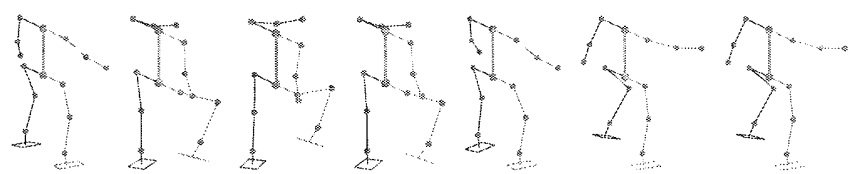

Fig. 5. Recovered Walking Motion using FHMM - Animated from recovered joint angle data using the trained walk motion model by the proposed method. $(1,11,21,31,41,51$ and 61 frames)

その運動データから 9 個の HMM と 9 個の FHMM が学習され た. 各 FHMM は 10 個状態ノードを持つ HMM 二つで構成される. それに対して違う数の状態ノードを持つ 3 種類の HMM を用いる. FHMM の学習の方法の中 [11] [12] [13], exact 学習方法 [11] を利 用する。 Kulić らは [4] 認識と生成の関して HMM と FHMM の比 較を行い，原始シンボルを明磪に区別するために原始シンボル空間 の混雑している領域では FHMM を使うことを提案した。本稿では 不観測データの復元の性:能の比較を中心に行う.

実験 1 では，各 FHMM は 10 個の状態ノ一ドを持つマルコフ チェーン二つで構成され，各 HMM は 20 個の状態ノードを持つ. 各運動は七つの複数のデータから学習される. 図 4 のように右半分 が見えない足踏みの観測デー夕を復元する。この観测データは学習 には使ってなかったデータである。図 5 は本稿で提案した FHMM を用いる方法からの復元した全身運動である。図 6 は左右䊫関節の 軦道を表す。観測データに対する最適な状態時系列から出力した平
均値で，スムージングを行う前の值である。この図から見られるよ うに，状態数が多い FHMM の方がシングルチェーンの HMM より よい精度を得ることが分かる。

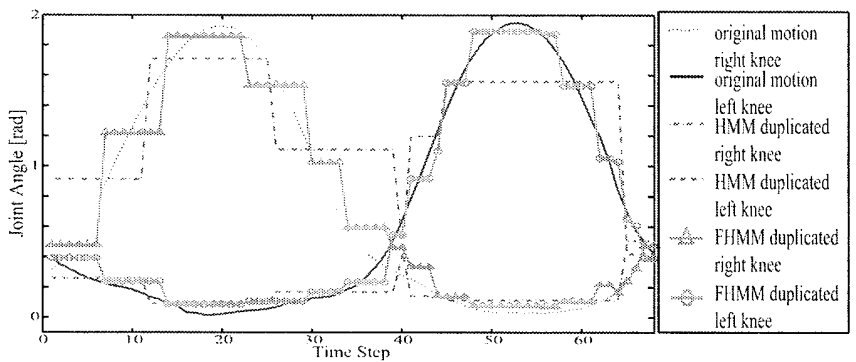

Fig. 6. Comparison of missing motion data recovery results of HMM (10 states) and FHMM (2 chains of 10 states) for the right and left knee joints during a walking motion. In observed data, joint angles for right half of the body was missing. Invisible right knee joint angle is recovered closely to the true value.

実験 2 では，FHMM は実験 1 と同様で，各 HMM は $10 \times 2$ 個 の状態ノードを持つ. 図 4 の部分観測データを用いて比較する。図 7 は復元後の左右膝関節の軦道を表す，スムージングを行う前の值 である.FHMM と HMM は両方とも 20 個の状態ノ一ドを持つが, FHMM は分散型状態を factorizing する事により最大 $10^{2}$ 個の状態 表現力を持つため, よい精度を得ることが分かる.

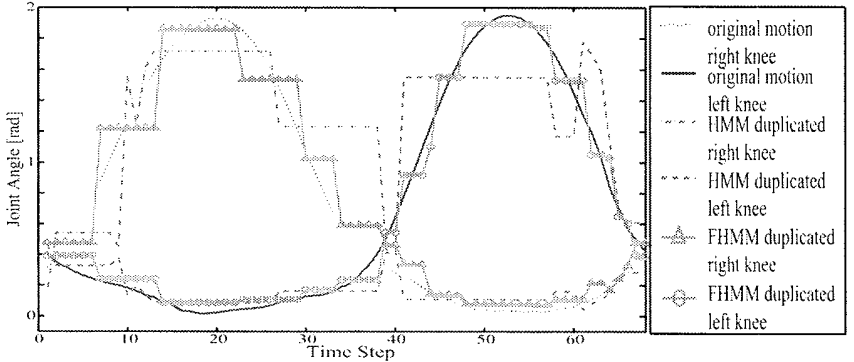

Fig. 7. Comparison of missing motion data recovery results of $\mathrm{HMM}(10 \times 2$ states) and FHMM ( 2 chains of 10 states) for the right and left knee joints during a walking motion, before any post processing is applied.

実験 3 では，FHMM は実験 1 と同様で，各 HMM は $10^{2}$ 個の状 態ノードを持つ. 図 4 の部分観測デー夕を用いて比較する. 図 8 は 復元後の左右膝関節の軦道を表す. FHMM の表現力に等しい $10^{2}$ 個の状態を HMM は持つが, FHMM が HMM よりよい精度を得た。 その理由は HMM は状態数が多くなると過学習に落ちりやすくな るからである。その結果新しい運動パターンに対する最適状態経路 の計算性能が悪くなる。反面に FHMM は新しい運動パターンに対 しても洲化性能に優れ，最適状態経路の計算性能もいい.

HMM を実装する際, 計算的なオーバーフローあるいはアンダー フローを回避するため，スケーリングパラメータ [15] と対数尤度 などを用いる。これ以外にも多くの研究で [16] [2] [4] 共分散行列 の対向化，最低共分散值の設定等の対策がとられている。才ーバー フローあるいはアンダーフローの理由の一つは HMM の過学習で ある. 実験 4 では, 複数のモデル構造に対して過学習の傾向を調 べるため，最低共分散制限なしの非対向共分敬行列 (full covariance matrix) 老用いる. 28 個の足踏み, 15 個の万歳, 14 個のダンス, 19 個のキック，14 個のパンチ，15 個の相撲のしこ，14 個のうずくま る，13 個の投げ，15 個のしゃがみこみから9つの行動が学習され た。各運動は次の八つのモデル構造へと学習された：周期型 HMM 
TABLE I

TRAINING SUCCESS RATIO WITHOUT OVER/UNDERFLOW [UNIT: \%]

\begin{tabular}{|c|c|c|c|c|c|c|c|c|}
\hline model & $\begin{array}{r}\text { periodic HMM } \\
10 \text { states }\end{array}$ & $\begin{array}{r}\text { periodic HMM } \\
20 \text { states }\end{array}$ & $\begin{array}{r}\text { periodic HMM } \\
100 \text { states }\end{array}$ & $\begin{array}{r}\text { periodic FHMM } \\
2 \text { chains of } 10 \text { states }\end{array}$ & $\begin{array}{r}\text { LR HMM } \\
10 \text { states }\end{array}$ & $\begin{array}{r}\text { LR HMM } \\
20 \text { states }\end{array}$ & $\begin{array}{l}\text { LR HMM } \\
100 \text { states }\end{array}$ & $\begin{array}{l}\text { left-to-right FHMM } \\
2 \text { chains of } 10 \text { states }\end{array}$ \\
\hline walk & $3 \overline{3}$ & 15.6 & 3.6 & 44.6 & 29.7 & 20.7 & 0 & 61 \\
\hline cheer & 100 & 100 & 32 & 100 & 100 & 99.4 & 0 & 100 \\
\hline dance & 100 & 100 & 32.6 & 100 & 100 & 100 & 0.3 & 100 \\
\hline kick & 100 & 98.8 & 29.6 & 100 & 99.9 & 99.5 & 0 & 100 \\
\hline punch & 100 & 100 & 46.67 & 100 & 100 & 100 & 0 & 100 \\
\hline SUMO & 100 & 100 & 33.67 & 100 & 100 & 99.8 & 0.2 & 100 \\
\hline squat & 100 & 100 & 39 & 100 & 100 & 99.7 & 0 & 100 \\
\hline throw & 100 & 100 & 41.8 & 100 & 100 & 99.8 & 0 & 100 \\
\hline bow & 100 & 100 & 26 & 100 & 99.8 & 98.4 & 0 & 99.9 \\
\hline
\end{tabular}

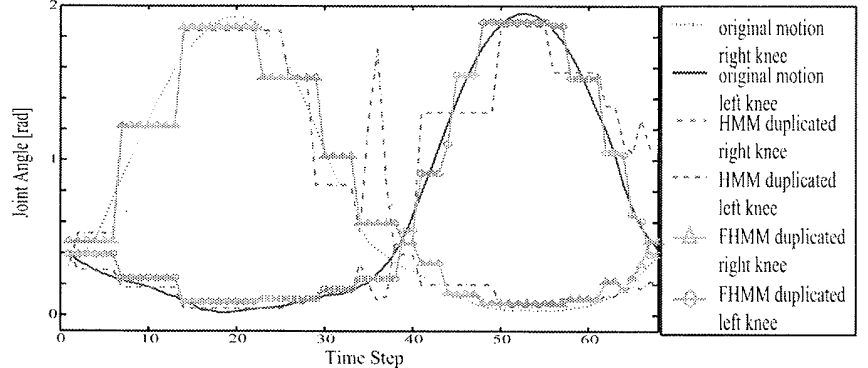

Fig. 8. Comparison of missing motion data recovery results of HMM $\left(10^{2}\right.$ states) and FHMM (2 chains of 10 states) for the right and left knee joints during a walking motion, prior to any post-processing.

（状態数 10），周期型 HMM（状態数 20），周期型 HMM（状態数 100），周期型 FHMM（状態数 10, チェーン数 2）， left-to-right 型 HMM (状態数 10), left-to-right 型 HMM (状態数 20), left-to-right 型 HMM（状態数 100）, left-to-right 型 FHMM（状態数 10, チェ一 ン数 2）。各運動の各モデルへの学習は 1000 回行い，その中で計 算的なオーバーフローあるいはアンダーフローの問題なく学習性効 率を調べ，表 I に示す。この表から，状態 10 個のマルコフチェー ン二つで構成されている FHMM が状態 10 個の HMMよりも過学 習に落ちにくいことが分かる. $10^{2}$ 個の状態を持つHMM は学習す ることが難しいことが分かる．上多くの状態を持つHMM は学習に 成功しても，抽象化した形で運動時系列を表現するミメシスモデル のシンボリック意味が弱くなる短所がある.

$$
\text { V.おわりに }
$$

本稿は FHMMs(factorial hidden Markov models) を利用して部分 観测データの不観测要素を復元する方法を提案した。この方法は 部分観測から全身運動見真似のアルゴリズムと類似な戦略をとる. 動作の表現力を改善できるFHMM を用いた，FHMM は分散型の 状態を持つため，過学習問題に落ちなく，よい動作表現ができる。 FHMM 用の Viterbi アルゴリズムを開発し，原始シンボルと観测 データに条件付けられた運動生成に適応した，実験では，人間の運 動を観察して見えない関節角の時系列を推定した。実験結果から， HMM に比べて FHMM の方が過学習問題なく復元の精度も改選す ることを確認した。

本研究は, 平成 18 年度科学研究費補助金基盤研究（S）「知能 の力学的情報処理モデルの展開」と文部科学省「先端融合領域イ， ベーション創出拠点の形成：少子高齢社会と人を支える IRT 基盤 の創出」の支援を受けて実施したものである.

\section{REFERENCES}

[1] W. Takano, H. Tanie, and Y. Nakamura, "Key feature extraction for probabilistic categorization of human motion patterns," in the 12th IEEE
International Conference on Advanced Robotics (ICAR'05), Seattle, USA, July 2005, pp. 424-430.

[2] W. Takano, K. Yamane, T. Sugihara, K. Yamamoto, and Y. Nakamura, "Primitive communication based on motion recognition and generation with hierarchical mimesis model," in IEEE International Conference on Robotics and Automation, Orland, Florida, USA, May 2006, pp. 36023609.

[3] T. Inamura, Y. Nakamura, and I. Toshima, "Embodied symbol emergence based on mimesis theory," International Journal of Robotics Research, vol. 23, no. 4, pp. 363-377, 2004.

[4] D. Kulić, W. Takano, and Y. Nakamura, "Representability of human motions by factorial hidden markov models," in IEEE/RSJ International Conference on Intelligent Robots and Systems(IROS'07), 2007.

[5] A. Billard, S. Calinon, and F. Guenter, "Discriminative and adaptive imitation in uni-manual and bi-manual tasks," Robotics and Autonomous Systems, vol. 54, pp. 370-384, 2006.

[6] D. Kulić, W. Takano, and Y. Nakamura, "Incremental on-line hierarchical clustering of whole body motion patterns," in IEEE International Symposium on Robot and Human Interactive Communication, 2007.

[7] K. R. Dixon, J. M. Dolan, and P. K. Khosla, "Predictive robot programming: Theoretical and experimental analysis," International Journal of Robotics Research, vol. 23, pp. 955-973, 2004.

[8] D. Lee and Y. Nakamura, "Mimesis from partial observations," in IEEE/RSJ International Conference on Intelligent Robots and Systems (IROS'05), Edmonton, Canada, August 2005, pp. 1911-1916.

[9] - "Mimesis scheme using a monocular vision system on a humanoid," in IEEE International Conference on Robotics and Automation (ICRA'07), Rome, Italy, April 2007, pp. 2162-2168.

[10] —, "Motion capturing from monocular vision by statistical inference based on motion database: Vector field approach," in IEEE/RSJ International Conference on Intelligent Robots and Systems(IROS'07), San Diego, USA, 2007, pp. 617-623.

[11] Z. Ghahramani and M. I. Jordan, "Factorial hidden markov models," in Machine Learning, vol. 29, 1997, pp. 245-275.

[12] R. A. Jacobs, W. Jiang, and M. A. Tanner, "Factorial hidden markov models and the generalized backfitting algorithm," Neural Computation, vol. 14, pp. 2415-2437, 2002.

[13] D. Kulić, W. Takano, and Y. Nakamura, "Incremental learning of full body motions via adaptive factorial hidden markov models," in 7 th International Conference on Epigenetic Robotics, 2007.

[14] L. R. Rabiner, "A tutorial on hidden markov models and selected applications in speech recognition," Proc. IEEE, pp. 257-286, 1989.

[15] H. Juang, B. and R. Rabiner, L., "A probabilistic distance measure for hidden markov modeling," AT\&T Tech. J., vol. 64, no. 2, vol. 64(2), pp. $391-408,1985$.

[16] D. Lee and Y. Nakamura, "Stochastic model of imitating a new observed motion based on the acquired motion primitives," in IEEE/RSJ International Conference on Intelligent Robots and Systems (IROS'06), Oct. 10-13 2006, pp. 4994-5000. 